\title{
Observatório da Comunicação Pública: pesquisa, crítica e cidadania
}

PUBLIC COMMUNICATION OBSERVATORY: RESEARCH, CRITICISM AND CITIZENSHIP

\section{Maria Helena Weber}

Professora do PPGCOM/FABICO/UFRGS e pesquisadora 1 do CNPq.

E-mail: maria.weber@ufrgs.br

\section{Ana Javes Luz}

Jornalista e doutoranda em Comunicação e Informação (PPGCOM/UFRGS).

E-mail: anajaves@gmail.com

Recebido em 31 de janeiro de 2017. Aprovado em 5 de abril de 2017.

\section{Resumo}

O objetivo deste artigo é refletir sobre o processo de criação, construção e funcionamento do site Observatório da Comunicação Pública (Obcomp) a partir de perspectivas teórico-práticas que relacionam temas de interesse público, cidadania e comunicação na democracia brasileira. Sediado no Programa de Pós-Graduação em Comunicação e Informação (PPGCOM) da Universidade Federal do Rio Grande do Sul (UFRGS), o eixo conceitual do Obcomp é a comunicação pública. Nessa direção, o debate e a crítica o constituem, uma vez que captura, classifica e disponibiliza informações sobre a comunicação de Estado e notícias de interesse público, além de acompanhar a radiodifusão pública.

Palavras-chave: Comunicação pública. Observatórios. Interesse público.

\section{Abstract}

The purpose of this article is reflect about the process of creation, construction and operation of the project Observatório da Comunicação Pública (Obcomp) based on theoretical-practical perspectives that relate themes of public interest, citizenship and communication in Brazilian democracy. Headquartered in Programa de Pós-Graduação em Comunicação e Informação (PPGCOM) from Universidade Federal do Rio Grande do Sul (UFRGS), Brazil, the conceptual axis of the Obcomp is public communication. In this direction, it's constitute of debate and criticism, since it captures, classifies and makes available information about state communication and news of public interest, besides to accompany public broadcasting.

Keywords: Public communication. Observatories. Public interest. 


\section{Introdução}

Este artigo tem por objetivo fazer uma reflexão sobre a comunicação pública a partir do processo de criação e manutenção do Observatório da Comunicação Pública (Obcomp $)^{1}$, projeto de monitoramento, captura, sistematização e crítica sobre temas de interesse público. Considera as premissas teóricas e as práticas que, ao longo dos seus primeiros 17 meses de funcionamento, permitiram a consolidação do projeto como espaço de produção crítica e difusão de conhecimento por meio de repositório da produção científica sobre comunicação pública e como lugar de debate, defesa e resistência da comunicação pública no Brasil.

O conceito norteador e de orientação do Obcomp é a comunicação pública concebida como instância de promoção do debate público sobre temas de interesse público, cujos dispositivos são indicadores de qualidade das democracias, com potencial mobilizador da opinião pública, da sociedade, das mídias hegemônicas e alternativas, da imprensa e das redes sociais. Nessa direção, o Obcomp busca atuar como dispositivo capaz de capturar essas informações - desenvolvidas pelo Estado (poderes executivo, legislativo e judiciário); pela sociedade; por acontecimentos e por movimentos de diferentes matizes políticas, para debatê-las e torná-las acessíveis, gerando novos debates e críticas, além de permitir a ampliação da pesquisa. Seu foco é responder a questões teóricas e demandas, a fim de obter resultados relacionados ao desenvolvimento de pesquisas nessa área do conhecimento.

Algumas premissas teóricas norteiam a reflexão sobre o Obcomp como instância de qualificação da cidadania, considerando os princípios da comunicação pública. A comunicação é inerente às práticas democráticas e à política que, para tanto, investe em tecnologia, recursos financeiros e profissionais voltados à definição de estratégias, produtos e ações de relacionamento, visibilidade, disputa e accountability em nome do interesse público. Nessa perspectiva, as relações com as mídias e com a sociedade são determinantes para a existência de um debate público, assim como a promoção de determinados projetos, a disputa de versões sobre acontecimentos políticos e a desejada imagem pública favorável.

Uma segunda premissa diz respeito à cidadania e ao debate público sobre políticas públicas engendradas pelos governos democráticos, que pretendem responder ao

1 O Obcomp está sediado na Universidade Federal do Rio Grande do Sul (UFRGS) e é vinculado ao Núcleo de Comunicação Pública e Política (Nucop), do Programa de Pós-Graduação em Comunicação e Informação (PPGCOM/UFRGS), de acordo com o projeto aprovado no edital MCTI/CNPq/MEC/Capes nº 43/2013. O Grupo de Pesquisa em Comunicação Organizacional, Cultura e Relações de Poder (Gccop) também participou do seu processo de implantação. O Obcomp é acessado através do site <www.ufrgs.br/obcomp $>$. 
interesse público conformado pela constituição brasileira e pela defesa de direitos humanos e sociais. No entanto, essas políticas são desenvolvidas, também, de acordo com interesses econômicos, privados e corporativos. Por isso é importante promover o debate com a sociedade, tendo em vista a compreensão dessas políticas e suas consequências, bem como o desequilíbrio quando as mídias hegemônicas adotam a perspectiva privada e corporativa, reduzindo o debate do qual são promotoras e mediadoras.

Por fim, uma terceira premissa é relacionada ao impacto e à repercussão das políticas públicas identificáveis em três níveis: nos produtos, ações estratégicas, discursos adotados e publicizados pelos órgãos estatais junto aos públicos; nas notícias e opiniões que repercutem aspectos das políticas públicas na imprensa; e, por último, no discurso das organizações privadas sobre as ações públicas. A existência dos observatórios permite criar instâncias de vigilância da democracia.

Diante dessa base teórica, as práticas do Obcomp obedecem aos princípios de um debate público com a exposição de abordagens sobre temas de interesse público e sobre comunicação pública, verificadas em seis operações inter-relacionadas: (i) monitoramento; (ii) análise e crítica; (iii) participação; (iv) produção científica; (v) acessibilidade; e (vi) divulgação.

Este artigo privilegia os aspectos teóricos relacionados às premissas da comunicação pública e às práticas do funcionamento do Obcomp. A pesquisa bibliográfica e a análise histórico-descritiva são processos que identificam a metodologia utilizada.

\section{Comunicação pública, a qualidade das democracias}

O Obcomp tem como base teórica o conceito de comunicação pública sediado na perspectiva habermasiana do debate público e na fronteira das teorias da democracia deliberacionista, especialmente a abordagem de Esteves $(2003 ; 2007 ; 2011)^{2}$. A qualificação e precisão sobre esse conceito significa analisar suas práticas e ampliar o debate existente pelo acúmulo teórico (ensino, produção científica, eventos e publicações) sem perder a normatividade da "esfera pública" na perspectiva de Habermas (1984; 1997), da "democracia deliberativa" (BOHMANN, 2000) e as complexas relações entre organizações midiáticas, instituições políticas e sociedade no Brasil. Desse modo, o Obcomp contribui para o debate público, princípio do Estado republicano, considerando que Estado, sociedade e mídia debatem temas relacionados ao interesse público, a políticas públicas ou a

2 A produção científica gerada pelos integrantes do Núcleo de Pesquisa em Comunicação Pública e Política (Nucop) indica avanços na interpretação e aplicação do conceito "comunicação pública". 
decisões políticas. Se a qualidade das políticas públicas permite avaliar a qualidade ou déficits da democracia, é o debate em torno desses temas que permite identificar os limites entre interesses públicos e privados do próprio Estado, da mídia e das organizações direta e indiretamente atingidas. A insistência em delimitar o uso do conceito comunicação pública se deve à necessidade de marcar diferenças entre interesses públicos e privados, isto é, quando o interesse público é reduzido a tema de interesses políticos e privados e, como tal, passam a orientar a produção de informação e, consequentemente, a mobilização de opiniões e ações em torno de decisões vitais.

Comunicação pública, assim como interesse público, é um conceito cuja semantização pode servir tecnicamente a qualquer ação oriunda de governos democráticos ou mesmo justificar a tomada de posição de órgãos de imprensa. Ao tentar ultrapassar a dimensão normativa do conceito, seus operadores simplificam e o reduzem a mídias, ações, produtos publicitários e informativos gerados pelas estruturas de comunicação governamental. Evidente que uma ação de comunicação produzida por um governo democrático poderá ser classificada quanto a seu inevitável caráter público, assim como aquelas dos veículos de radiodifusão pública. No entanto, é importante identificar os limites dessa comunicação pública, ou seja, sua capacidade de promover o debate público sobre o tema em curso ou a limitação desse debate em torno de decisões pré-agendadas; promover a comunicação em benefício da sociedade ou dirigida à formação de imagem pública favorável; e divulgar informações ou investir em propaganda. Não são decisões excludentes à primeira vista, mas perspectivas que apontam para o paradoxo da visibilidade (WEBER; CARNIELLI, 2016), quando interesses públicos e privados de uma instituição pública aparecem inter-relacionados, seja na projeção do governante sobre o projeto ou em sua defesa por setores da imprensa, sem que a sociedade seja ouvida para o debate público. A circulação de opiniões e de informações, em escalas nacional, regional e local, por rádios, televisão, jornais, revistas e internet incidirão na formação da imagem pública, cuja repercussão poderá gerar votos, apoio e índices de aprovação. Por isso, a experiência do Obcomp tem contribuído com a comunidade científica na reflexão sobre essas questões, na medida em que a própria produção sobre comunicação pública tem sido capturada e disponibilizada em seu repositório.

A comunicação pública é da lógica política e ocorre quando Estado, sociedade e mídias ingressam num debate sobre temas relacionados ao interesse público, à política pública ou a decisões políticas que interferem na vida das pessoas e na organização social. Diferentes indicadores de estratégias discursivas e manifestações na esfera de visibilidade pública permitiriam identificar quais temas possuem validade nos âmbitos da política, da mídia e da sociedade, sendo capazes de formar e manter uma rede de comunicação pública. É 
a política pública que permite avaliar a qualidade ou os déficits da democracia, mas é o debate sobre ela que permite identificar os limites entre interesse públicos e privados do próprio Estado, da mídia e das organizações direta e indiretamente atingidas. Nas redes de comunicação pública (WEBER, 2011), encontram-se objetivos, estratégias e discursos próprios da comunicação estatal (produzida pelos sistemas, mídias e produtos da comunicação dos poderes, assim como por instituições públicas e atores da política); da comunicação midiática (produzida por meios de comunicação massivos e pela imprensa); e da comunicação institucional (produzida por instituições sociais e organizações privadas).

A comunicação pública enquanto perspectiva normativa se constitui na "esfera de visibilidade pública" (GOMES, 2008), quando o Estado promove ou ingressa num debate público com a participação da sociedade (redes sociais, discursos e manifestações) e dos sistemas midiáticos (hegemônicos e alternativos), fazendo, assim, com que sejam respeitados e se encaminhem argumentos e emoções em torno de determinado tema vital. Essa normatividade permite entender os limites da comunicação das democracias, cujos poderes mantêm sofisticados e competentes aparatos de produção de informação e propaganda com profissionais, tecnologias e competências próprias do campo da comunicação.

O desenvolvimento das pesquisas já permite elaborar a hipótese sobre as relações entre Estado, meios de comunicação de massa e sociedade a partir da comunicação sobre temas de interesse público, considerando a repercussão e a credibilidade sobre as ações e discursos dos poderes executivo, legislativo e judiciário. Fatos e informações desses poderes dependem da homologação das mídias e da sua inclusão a partir de critérios jornalísticos que, em tese, obedecem à verdade. Essa homologação também dependerá da abertura de espaços de visibilidade a partir dos interesses econômicos, políticos e privados de organizações de comunicação. De qualquer modo, é o jornalismo que importa, considerando suas funções relacionadas ao interesse público e aos processos de vigilância do Estado. Por esse motivo, as estruturas de comunicação dos poderes precisam produzir, essencialmente, material jornalístico para alimentar as próprias mídias e as redes de comunicação dirigida, o que fazem com um grande número de profissionais, investimentos, e com o auxílio da tecnologia. As demais competências - marketing, propaganda e relações públicas -, mesmo que mais sofisticadas e com vultuosos investimentos, servem a objetivos de ordem persuasiva ou como apoio estético à informação de caráter público.

Para Weber (2011), a problematização sobre a comunicação pública é formulada entre as dimensões da normatividade e da funcionalidade, a partir de três questões basilares: o paradoxo da visibilidade é a primeira, que está nos limites e sobreposições entre público e privado na publicização de ações públicas, discursos políticos e mídias dos poderes e instituições públicas. Enquanto o poder da tecnologia e a qualidade dos 
complexos sistemas de informação profissionalizaram e deram autonomia à comunicação dos poderes, as exigências de transparência, participação e accountability - inerentes à democracia - somaram-se às estratégias em busca da imagem pública adequada à disputa de opiniões e votos.

A segunda questão, o poder da imprensa, está vinculada à relação entre instituições democráticas e o papel de vigilância e mediação desempenhado pelo jornalismo. Essa condição, própria da imprensa, poderia indicar que o interesse público seria defensável em quaisquer circunstâncias, preservadas a liberdade e autonomia de pensamento e opinião. No entanto, a produção científica sobre agendamentos e enquadramentos demonstram as contradições sobre a posição da mídia em relação ao interesse público, assim como a defesa de seus próprios interesses sobre a política.

E, por fim, a dicotomia público-privado, que está centrada em proposição, reação, comunicação e ações provocadas por instituições sociais e organizações privadas a partir de políticas ou ações públicas. Essas instituições e organizações privadas podem ingressar no debate público a partir de manifestações do Estado e da mídia, bem como podem abordar um determinado tema de interesse público como evento ou campanha publicitária para provocar o Estado, atrair a mídia, ou ser produzido pelas próprias organizações midiáticas, pois as estratégias das empresas em torno da promoção do interesse público - que lhes convêm - transformaram-se em referência para colaborar com projetos e temas da alçada do Estado, com espaço garantido na mídia. Por outro lado, sindicatos de classe e associações diversas fazem greves e manifestações de ruas, como também tentam dialogar com o Estado mas apenas eventualmente recebem cobertura midiática.

Os "princípios e objetivos da radiodifusão pública", definidos no Art. $2^{\circ}$ da Lei 11.652/2008 (BRASIL, 2008), explicitam muito bem a relação entre cidadania, exercício democrático e comunicação pública, ao exigirem a "promoção do acesso à informação por meio da pluralidade de fontes de produção e distribuição do conteúdo"; a "não discriminação religiosa, político partidária, filosófica, étnica, de gênero ou de opção sexual" e a "participação da sociedade civil no controle da aplicação dos princípios do sistema público de radiodifusão, respeitando-se a pluralidade da sociedade brasileira", entre outros.

Compreender a dimensão normativa da comunicação pública significa, portanto, promover a cidadania, cujo estatuto é definidor da democracia e está relacionado à participação social. Nessa perspectiva, cidadania é também conceito instituinte da comunicação pública e, operacionalmente, a participação da sociedade no debate sobre temas de interesse público qualifica a democracia. Na perspectiva epistemológica, é o exercício da cidadania que tensiona a comunicação pública. 


\section{Observatórios: espaços de cidadania}

Os observatórios foram temas de pesquisa abordados por Braga (2006), Christofoletti e Motta (2008) e Téllez (2011), com análise focada especialmente na imprensa e no jornalismo. A crítica à mídia acompanha os estudos sobre comunicação desde seu ingresso como campo científico e o poder das mídias de massa e a relação entre difusão de informações, propaganda e a opinião pública ainda são temas complexos e atuais.

Os observatórios que vigiam as mídias são entendidos por Braga (2006, p. 36) como interação entre mídia e a sociedade, a qual se organiza "para tratar a própria mídia, desenvolvendo dispositivos sociais com diferentes graus de institucionalização, que dão consistência, perfil e continuidade a determinados modos de tratamento [...]". Segundo o autor, o exercício da crítica permite a defesa de valores sociais e o enfrentamento da mídia.

A identificação de observatórios e ouvidorias por Téllez (2011, p. 74-75) aponta para três aspectos importantes para se pensar o tema. Primeiro, a diversidade de especialistas, profissionais e pesquisadores empenhados na reflexão sobre "temas e problemáticas que interpelam a esfera pública comunicativa da democracia" possui "um caráter particularmente propositivo na medida em que, ao fazer uma aproximação às suas lógicas de produção e rotinas jornalísticas, busca-se diminuir alguns dos efeitos gerados pela crescente concentração midiática". Depois, ressalta "o sistema de informação gerado pelos observatórios que tem como ferramenta fundamental a presença das tecnologias de informação e comunicação" que permitiria "contato e interação permanente com seus usuários". Por último, aponta para o "trabalho pedagógico" dos observatórios realizados em instituições de ensino e pesquisa, salientando que "é particularmente importante no interior das faculdades de comunicação". No Brasil, o Observatório de Imprensa, criado e dirigido por Alberto Dines em 1996, no Laboratório de Estudos Avançados em Jornalismo (Labjor) da Universidade Estadual de Campinas (Unicamp), é precursor da prática das críticas à mídia. Experiência cidadã nos anos de retomada da democracia brasileira, com dispositivos de fortalecimento da cidadania em benefício do interesse público, está até hoje em funcionamento.

O conceito de cidadania está vinculado ao conceito de comunicação pública devido à expectativa do debate público e da participação social. Nesse sentido, a tensão entre os dois é provocada pela complexidade dos elementos que os instituem, com diferentes objetivos, valores, interesses, relações, classes, cultura, responsabilidades e modos de participação nos processos e instituições da democracia contemporânea. O que une esses conceitos e as práticas vinculadas é a variável política e os cenários históricos que permitem identificar seus movimentos. 
Bobbio $(1987$; 1986) define o público como aquilo que beneficia a todos os cidadãos, promovendo valores e direitos. Independente das apropriações funcionais e da polissemia do termo, o conceito se mantém essencial para estabelecer o reconhecimento e a dicotomia entre o público e o privado. Democracia se faz com a sociedade e sua participação é o próprio exercício de cidadania. A evolução da democracia e o fortalecimento da cidadania no Brasil atraem Dagnino (2000), que mostra a complexidade das democracias e problematiza a cidadania nas relações entre democracia (de frágil consolidação) e a sociedade civil, insatisfeita pela falta de resultados em relação à participação, justiça e inclusão política.

Relacionar cidadania à comunicação pública e a observatórios é trazer à tona os debates sobre o direito à comunicação e à informação que desde a década de 60 mobilizam instituições sociais, acadêmicas e políticas, gerando documentos e legislações que, em tese, garantem esses direitos. No entanto, o poder das mídias de massa/hegemônicas mantém o espaço aberto sem que as conquistas jurídicas e políticas tragam resultados concretos na participação do cidadão quanto ao controle das mídias de concessão pública e seu acesso à informação.

Os observatórios são, portanto, dispositivos que permitem tensionar os indicadores de qualidade das democracias, da mídia hegemônica e da comunicação do Estado, à medida que o interesse público é a variável central, pois todas essas instâncias de produção da comunicação são norteadas pelo interesse público. Se a diluição contemporânea entre interesses públicos e privados não altera significativamente a estrutura das democracias, a defesa da comunicação pública é o indicador de qualidade do sistema democrático, pois podem ser identificados temas, atores, meios e estratégias em debate ou em um pseudodebate público.

A necessidade de mapear e identificar esses processos, tão caros aos campos da comunicação, ciência política e sociologia justifica a construção do Obcomp e a convergência de diferentes pesquisadores. Justificativa que pode ser ampliada com a constatação de que essas informações estão disponíveis para que sejam estudadas, fortalecendo sua importância para os campos científico e político. O Obcomp foi concebido e está organizado no sentido de privilegiar a comunicação pública e defender os princípios da cidadania. Esta é a experiência.

\section{A construção do Observatório da Comunicação Pública}

O Obcomp foi idealizado pelo Núcleo de Comunicação Pública e Política (Nucop) a partir da constatação do baixo índice de registros e da dispersão de dados sobre experiências e pesquisas relacionadas à comunicação pública. O projeto respondeu à necessidade de criar um espaço que capturasse, organizasse e disponibilizasse essa produção, 
bem como exercitasse o debate público sobre temas de interesse público, tornando esse material disponível a pesquisadores e cidadãos. Assim, o Obcomp adotou por objetivo monitorar temas de interesse público e sua repercussão em meios de comunicação de massa, na imprensa, na sociedade e em sistemas de comunicação do Estado, a fim de fomentar debates e disponibilizar a produção científica na área da comunicação pública em um único espaço (Figura 1).

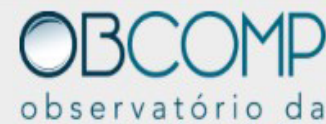

observatório da comunicação pública

Apresentação Editorial Nucop Gccop Legislação Fórume Debates Contato

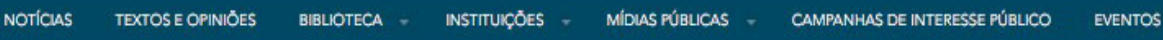

Notícias

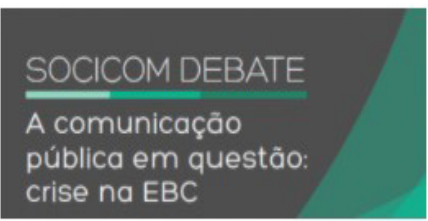

25 de janeliro de 2017

SOCICOM lança livro sobre crise da EBC

19 de janeiro de 2017

Frente Jurídica fala de ataque a direitos trabalhistas e ao patrimônio público pelo governo Sartori

A Frente Juridica em Defesa das Fundaçes anunciou que esta preparando uma série de açoes na Justiça comum para contestar a extinçáo dessas instituiços, dentre 8 qu quais se encontra a Fundaçăo Cultura Piratini - TVE e FM Cultura.

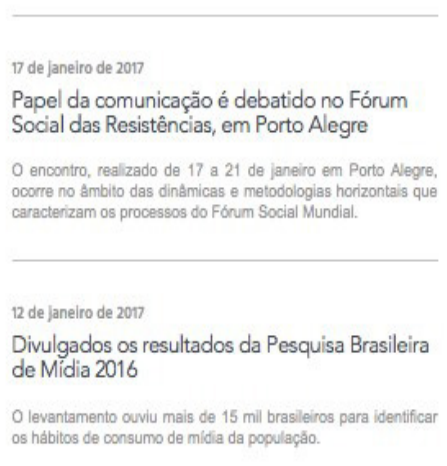

Textos e Opiniões

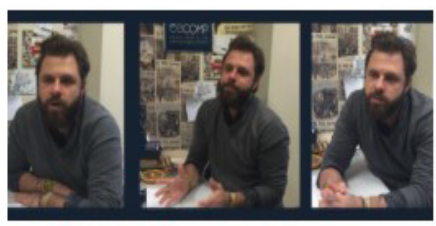

Felipe Milanez: O jornalismo legitima a violência contra os índios no Brasil

Campanhas de Interesse Público

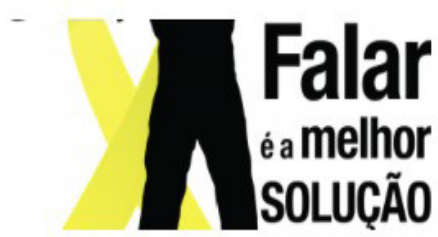

Setembro Amarelo e a Prevenção do Suicídio

Eventos

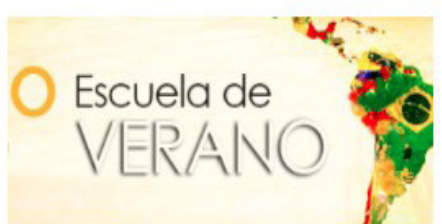

4a. Escola de Verão ALAIC
Fórum e Debates

A responsabilidade dos media e a crise política brasileira

\section{Comente}

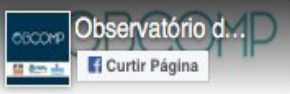

Seja o primeiro de seus amigos a curtir

isso.

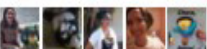

abservatório da Comunicação Pública 25 de janeiro às $15: 12$

A Federação Brasileira das Associaçōes Científicas e Acadêmicas de Comunicação (SOCICOM) lançou o segundo volume de uma série de ebooks que tem por objetivo promover e registrar discussōes sobre temas importantes para 0 fortalecimento do campo da Comunicaçäo. 0 tema desta

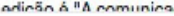

Receba nossa newsletter

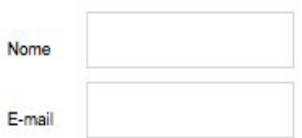

Figura 1. Página inicial do site do Observatório da Comunicação Pública

Fonte: www.ufrgs.br/obcomp

A implantação do projeto obedeceu a dois grandes objetivos: primeiro, o exercício da crítica relacionada a fatos, informações, propaganda e produtos que abordem 
temas de interesse público; depois, o compartilhamento de informações em repositório que organiza, classifica e disponibiliza informações sobre processos, pesquisas, produção científica, organizações, sistemas e produtos relacionados a instituições públicas, interesse público e à comunicação. Os conteúdos são organizados em torno do eixo temático "interesse público", a partir de produtos de comunicação como a comunicação institucional produzida pelo Estado, governos, instituições e atores da política; a comunicação midiática que abrange a programação e editorias das mídias hegemônicas e alternativas; a comunicação organizacional produzida por empresas privadas e entidades representativas que reagem de modo positivo ou negativo a políticas públicas de comunicação.

A primeira etapa para a concretização do projeto constituiu-se por: captura e classificação de dados e informações sobre a produção científica ligada à comunicação pública; informações sobre legislação, sistemas de comunicação do Estado e meios públicos de comunicação; campanhas publicitárias de utilidade pública ou vinculadas a temas de interesse público. Essas informações atendem ao objetivo do Obcomp de funcionar como repositório de conhecimento científico e estão disponíveis para acesso público nas seguintes seções: Biblioteca, Campanhas de Interesse Público, Legislação, Instituições, Mídias Públicas, Notícias, Eventos, Textos e Opiniões. O mapa do site do Obcomp (Figura 2) reúne a identificação de cada seção e a quantidade de peças ali armazenadas até o momento ${ }^{3}$.

Além disso, dois conselhos garantem o cumprimento dos objetivos do Obcomp e a solidez do projeto: o Conselho Consultivo e o Conselho Deliberativo, constituídos por dezenas de professores e pesquisadores ${ }^{4}$ ligados a universidades nacionais e internacionais. A estrutura técnica é mantida por pesquisadores, docentes, doutorandos e mestrandos do Nucop e alunos de iniciação científica vinculados.

O site também oferece uma ferramenta para facilitar o compartilhamento de notícias, eventos, textos e opiniões nas principais redes sociais, além de fanpage na rede social Facebook ${ }^{5}$, na qual são divulgadas as atualizações. A interface entre website e redes sociais proporciona fluxo permanente de acessos entre usuários frequentes e ocasionais. O material disponibilizado contribui decisivamente para pesquisa, produção científica e docência se o tema for comunicação pública.

3 Dados contabilizados até 25 de janeiro de 2017.

4 Mais informações disponíveis em <www.ufrgs.br/obcomp/apresentacao>

5 Disponível em: <www.facebook.com/obcompp>. Acesso em: 12 jun. 2017.

$10 \frac{\text { Comunicação \& Inovação, PPGCOM/USCS }}{\text { v. 18, n. } 37 \text { (1-17) maio-ago } 2017}$ 


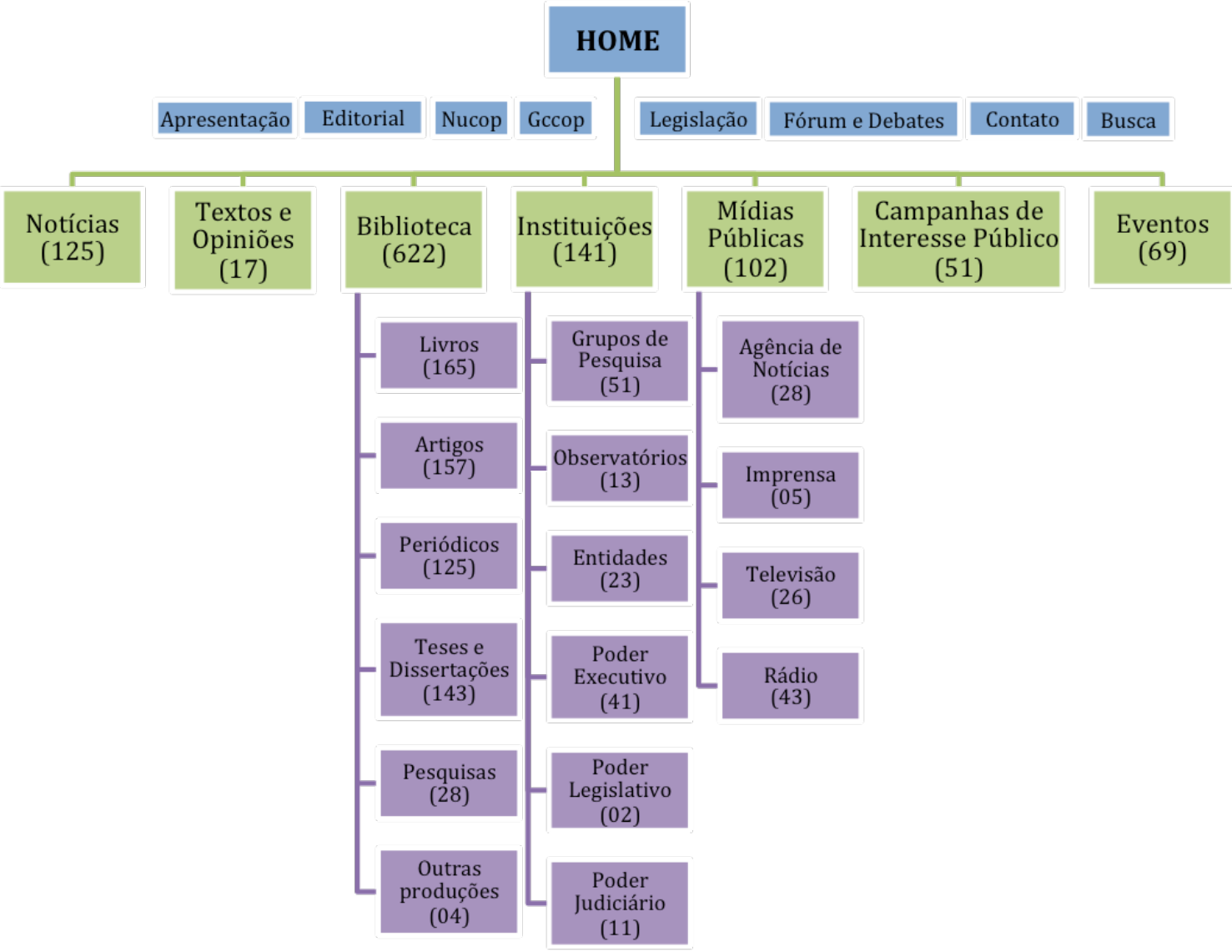

Figura 2. Mapa do site do Observatório da Comunicação Pública

Fonte: desenvolvido pelas autoras

\section{Um exercício de vigilância: o monitoramento em defesa da comunicação pública}

O Obcomp busca contribuir para a reflexão e a produção de conhecimento nos campos da comunicação, da sociologia e da ciência política. Porém, seu eixo conceitual é a comunicação pública, em que produz o maior impacto, na medida em que monitora, produz conteúdo e expõe diferentes debates sobre temas de interesse público relacionados a essa área do conhecimento. Nessa perspectiva, relataremos importante experiência de monitoramento no campo da política.

O cenário de implantação do Obcomp foi sendo formado pelos diferentes processos da recente crise política brasileira. Iniciada em $2013^{6}$, essa crise atravessou a reeleição da presidenta Dilma Rousseff, em 2014; as manifestações públicas em todo o

6 As manifestações de 2013 no Brasil, inicialmente contra o aumento de passagens do transporte coletivo municipais, são consideradas um marco da recente história das relações entre sociedade, Estado e mídias. 
país, em 2015 e 2016; agravando-se com o polêmico processo de impeachment que afastou a presidenta e empossou o vice-presidente Michel Temer. O novo governo investiu contra a comunicação pública, com destaque para as intervenções na Empresa Brasil de Comunicação (EBC) - fatos que o Obcomp monitorou, debateu, divulgou e criticou.

Os resultados deste trabalho se constituem em material privilegiado de pesquisa. Analisando os temas das notícias publicadas pelo Observatório desde sua criação (Quadro 1) e das 125 matérias disponíveis no site do projeto, cerca de 30\% (38 matérias) são relativas à defesa, avanços, ameaças ou retrocessos nos sistemas de comunicação pública do Brasil municipais, estaduais ou federal. Entre essas notícias, 81,5\% (31 notícias) foram publicadas após o impeachment da presidenta Dilma Rousseff pelo Senado e o início do governo interino de Michel Temer - momento a partir do qual o papel da comunicação pública entra fortemente na pauta de debates políticos, acadêmicos e midiáticos no Brasil.

Além de monitorar e produzir notícias sobre as mudanças no sistema federal de comunicação pública, o Obcomp também passou a acompanhar e debater, a partir de novembro de 2016, a ameaça de desmonte do sistema de comunicação pública do Estado do Rio Grande do Sul - pauta que se impôs quando o governador do Estado, José Ivo Sartori, encaminhou à assembleia estadual um projeto de lei autorizando a extinção da Fundação Piratini, que compreende a TV Educativa e a FM Cultura do Rio Grande do Sul. O projeto, aprovado pelos deputados estaduais em dezembro de 2016 e sancionado pelo governador em janeiro de 2017, autorizou a demissão de todos os funcionários concursados da Fundação e o encerramento das atividades da TV e rádio públicas do Estado, em funcionamento há quase 50 anos. Durante o período de debate público ocorrido na imprensa, no governo e na sociedade - desencadeado a partir do envio do projeto do executivo à assembleia -, o Obcomp publicou oito notícias e um editorial sobre o assunto, sempre se posicionando contrariamente ao fechamento das emissoras.

Quadro 1. Notícias sobre comunicação pública no Brasil publicadas no Obcomp

\begin{tabular}{|c|c|}
\hline Tífulo & Data \\
\hline Seminário discute comunicação pública em São Paulo & $13 / 10 / 2015$ \\
\hline UFG realiza Seminário Comunicação Pública e Cidadania & $18 / 11 / 2015$ \\
\hline Audiência pública no Senado discute a comunicação no Brasil e criação de novos canais públicos & $24 / 11 / 2015$ \\
\hline Câmara dos Deputados debate a comunicação pública no Brasil & $13 / 12 / 2015$ \\
\hline Encontro discutirá comunicação pública em Pernambuco & $16 / 02 / 2016$ \\
\hline Estado da Bahia pode ter plano estadual de comunicação elaborado em parceria com a sociedade civil & $06 / 04 / 2016$ \\
\hline Entidades se posicionam contra alterações na Lei Geral de Telecomunicações & $13 / 04 / 2016$ \\
\hline
\end{tabular}


Quadrro 1. Continuação

\begin{tabular}{|c|c|}
\hline Tífulo & Data \\
\hline Aula pública debate o futuro da EBC e da comunicação pública no Brasil & $21 / 05 / 2016$ \\
\hline Funcionários da $\mathrm{EBC}$ denunciam censura nos primeiros dias do governo interino de Michel Temer & $23 / 05 / 2016$ \\
\hline Obcomp publica novo editorial em defesa da comunicação pública & $24 / 05 / 2016$ \\
\hline $\begin{array}{l}\text { Trabalhadores da TVE e da FM Cultura fazem paralisação na próxima segunda (30) contra ameaça ao } \\
\text { caráter público das emissoras }\end{array}$ & $24 / 05 / 2016$ \\
\hline $\begin{array}{l}\text { Em audiência pública, jornalistas criticam exoneração de presidente da Empresa Brasileira de } \\
\text { Comunicação }\end{array}$ & $27 / 05 / 2016$ \\
\hline Conselho de Comunicação do Congresso irá realizar seminário sobre Comunicação Pública & 07/06/2016 \\
\hline Em audiência pública, defesa da EBC e da comunicação pública sai fortalecida & $22 / 06 / 2016$ \\
\hline Conselho de Comunicação Social do Congresso lança nota de apoio à EBC & 05/07/2016 \\
\hline $\begin{array}{l}\text { Conselho do Congresso critica suposta intenção do governo de acabar com Empresa Brasil de } \\
\text { Comunicação }\end{array}$ & $08 / 08 / 2016$ \\
\hline Câmara aprova Medida Provisória que extingue Ministério das Comunicações & $31 / 08 / 2016$ \\
\hline Governo Temer inicia desmonte da Empresa Brasileira de Comunicação & $02 / 09 / 2016$ \\
\hline Nota de repúdio à censura na Rádio da UFRGS & $12 / 09 / 2016$ \\
\hline Sociedade civil cobra participação na regulamentação da EMC & $01 / 10 / 2016$ \\
\hline Procuradoria Federal dos Direitos do Cidadão defende inconstitucionalidade de MP que alterou EBC & $10 / 10 / 2016$ \\
\hline Conselho de Comunicação do Congresso critica MP que acaba com Conselho Curador da EBC & $13 / 10 / 2016$ \\
\hline Na UFMG, debate aborda a comunicação pública na democracia brasileira & $18 / 10 / 2016$ \\
\hline Parque da Redenção recebe atividade em defesa da TVE e da FM Cultura & $08 / 11 / 2016$ \\
\hline Câmara dos Deputados conclui votação que flexibiliza exibição da Voz do Brasil & $18 / 11 / 2016$ \\
\hline Governo do RS quer extinguir emissoras públicas & $23 / 11 / 2016$ \\
\hline Projeto de fechamento das emissoras públicas do RS enfrenta resistência da sociedade & $28 / 11 / 2016$ \\
\hline Representantes da sociedade civil criticam reestruturação da EBC & $30 / 11 / 2016$ \\
\hline Conselho cassado da EBC divulga nota contra Medida Provisória que esfacela caráter público da empresa & $08 / 12 / 2016$ \\
\hline $\begin{array}{l}\text { Parecer de Lasier Martins sobre MP troca Conselho Curador da EBC por Comitê Editorial e de } \\
\text { Programação e desfigura empresa }\end{array}$ & $09 / 12 / 2016$ \\
\hline Sociedade gaúcha segue mobilizada contra extinção das emissoras públicas do Estado & $13 / 12 / 2016$ \\
\hline Comunicação Pública é tema de audiência na Assembleia Legislativa de Minas Gerais & $14 / 12 / 2016$ \\
\hline Câmara Federal aprova MP que altera a Empresa Brasil de Comunicação (EBC) & $16 / 12 / 2016$ \\
\hline Obcomp publica novo editorial em defesa do sistema de comunicação pública do RS & $19 / 12 / 2016$ \\
\hline $\begin{array}{l}\text { Projeto de lei que extingue a Fundação Piratini - TVE e FM Cultura - e mais } 5 \text { fundações gaúchas é } \\
\text { aprovado }\end{array}$ & $21 / 12 / 2016$ \\
\hline Cientistas, intelectuais e artistas lançam carta aberta ao governo do RS contra extinção de fundações & $10 / 01 / 2017$ \\
\hline Frente Jurídica fala de ataque a direitos trabalhistas e ao patrimônio público pelo governo Sartori & $19 / 012017$ \\
\hline SOCICOM lança livro sobre crise da EBC & $25 / 01 / 2017$ \\
\hline
\end{tabular}

Fonte: desen,volvido pelas autoras 
Posicionar-se em relação a uma medida ou política pública de comunicação integra as funções do Obcomp, que dispõe da seção "Editorial" para divulgar os textos assinados pela coordenação geral do projeto. Em 19 de dezembro de 2016, o editorial se posiciona sobre a ameaça de extinção da Fundação Piratini, no qual afirma:

Os sistemas de comunicação pública - identificados na radiodifusão pública e nas estruturas de comunicação do estado republicano - são essenciais à veiculação de conteúdos sobre a diversidade da cultura nacional, regional e, também, espaço de opiniões que permitem reconhecer a pluralidade da sociedade. Por mais difícil que seja a gestão de emissoras públicas, a potencialidade de sua programação reside na sua autonomia em relação ao mercado. [...] É preciso defender o papel destas instituições na constituição desse Estado; promover os avanços das pesquisas ali realizadas e alertar para a submissão das informações às leis do mercado, se o ato incompreensível, desmesurado e perverso de extinção da Fundação Piratini se concretizar no dito parlamento gaúcho. (WEBER, 2016)

Selecionar pautas e entrevistados; monitorar temas de interesse público, em especial aqueles ligados à comunicação pública; posicionar-se contra ou favoravelmente, com argumentos claros, a medidas propostas pelo Estado que impactam o sistema de comunicação pública é fomentar o debate público. O Obcomp foi desenvolvido para ser, além de espaço de catalogação e difusão de pesquisas científicas, uma plataforma de discussão e circulação de informações de interesse público. Nesse sentido, quanto mais informações, mais qualificado é o debate público, prática que fortalece os sistemas democráticos e deve marcar os processos da comunicação pública.

O Obcomp, ao atuar com o monitoramento de temas e instituições, permite qualificar e delimitar o conceito comunicação pública por ampliar o debate existente, gerando acúmulo teórico a partir da exposição das práticas desenvolvidas pelas instituições. Na perspectiva técnica, levantar dados e informações, agrupá-los, criticá-los, debatê-los e facilitar acesso, via dispositivo como o Obcomp, significa pesquisar um dos processos mais complexos sobre as relações, direitos e deveres dos poderes públicos para com a sociedade.

Identificar e analisar a produção da comunicação pública do Estado brasileiro permite problematizar questões de ordem ética (limites entre o público e o privado); de ordem estética (qualidade da produção nas emissoras públicas); de ordem profissional (formação de técnicos e especialistas, como também ampliação do campo de trabalho no Estado); de ordem técnica (espaços e sistemas das tecnologias da informação e comunicação); e de ordem da comunicação política (limites da informação, propaganda e publicização). São questões complexas que exigem referencial teórico e investigação empírica acurada para abordá-las, ou seja, para identificar os limites e convergências entre público 
e privado quando o assunto é a comunicação de governo, a autonomia da informação de governo e das grandes mídias, a abrangência da comunicação pública e a estrutura financeira, profissional e tecnológica que sustenta a comunicação das instituições.

\section{Considerações finais}

A criação e implementação do Obcomp permite acompanhar, monitorar, organizar e tornar acessíveis informações e caminhos sobre a comunicação pública e as respectivas instâncias para sua produção. Nesse sentido, contribui para a qualidade da produção científica, para a formulação da crítica e para o debate sobre temas de interesse público constitutivo da qualidade da democracia. $\mathrm{O}$ acúmulo de informações oferece subsídios para a reflexão sobre a precisa relação entre direito à informação, à comunicação e à cidadania.

A experiência aqui relatada abriga, ao mesmo tempo, um acervo no campo da comunicação pública e uma crítica contextual sobre temas de interesse público associados a instituições e mídias massivas. O funcionamento do Obcomp depende de debates e avaliações contínuas entre os grupos envolvidos no monitoramento de temáticas e a produção das instituições relacionadas à comunicação pública, à comunicação de governo e ao interesse público (direitos humanos, igualdade social, educação, segurança, justiça, saúde, economia familiar, ecologia, trabalho/emprego, liberdades democráticas, relações internacionais, economia de mercado, comunicação, entre outros). O projeto se consolida como repositório de pesquisas e demais produções científicas da área, catalogando e disponibilizando para livre acesso a produção intelectual no formato de teses, dissertações, publicações e produtos técnicos e científicos.

O Obcomp é um espaço destinado ao debate público e ao acúmulo teórico sobre comunicação pública, permitindo o exercício da cidadania ao reunir e disponibilizar informações sobre: comunicação do Estado; relações entre mídia, sociedade e Estado; estruturas e meios de produção de comunicação estatal e governamental; produção intelectual vinculada às práticas da comunicação pública, sem similares na área acadêmica. $\mathrm{O}$ material disponibilizado permite aprofundar o conceito de comunicação pública para além da comunicação de Estado e, nesse sentido, propicia debates e aprendizados contínuos.

A circulação de informações e críticas no espectro da comunicação pública mantém em evidência o debate público sobre o poder dos meios de comunicação e das redes sociais em relação à constituição da cidadania, da democracia e das formas de comunicação do Estado e suas instituições. Este é o impacto: a acessibilidade a endereços, sistemas e produção de comunicação pública que pode qualificar a produção científica e a compreensão das relações políticas, através de processos e debates de comunicação. 
Com a hipótese ordinária sobre a diluição acelerada entre interesses públicos e privados, é preciso demarcar a supremacia do público sobre o privado e entender seus limites quando o Estado se comunica, quando a sociedade se manifesta e quando as mídias participam do debate. Assim, o problema principal reside em questões relacionadas aos principais atores do debate político numa esfera pública e à identificação da comunicação pública.

O funcionamento desse projeto permite experimentar a hipótese de que a comunicação pública ocorre somente quando esses três níveis (Estado, sociedade e mídia) debatem temas relacionados ao interesse público, à política pública ou a decisões políticas. Por isso, a necessidade de mapear e identificar os processos de comunicação pública, tão caros à comunicação, à ciência política e à sociologia, criou a estrutura do Obcomp e o mantém como centro vital de pesquisa, crítica e cidadania.

\section{Referências}

BLUMLER, J. G.; GUREVITCH, M. The crisis of public communication. London: Routledge, 1995.

BOBBIO, N. Estado, governo, sociedade: para uma teoria geral da política. Rio de Janeiro: Paz e Terra, 1987.

. O futuro da democracia: uma defesa das regras do jogo. Rio de Janeiro: Paz e Terra, 1986.

BOHMAN, J. Public deliberation: pluralism, complexity and democracy. Cambridge, MA: MIT Press, 2000

BRAGA, J. L. A sociedade enfrenta sua mídia: dispositivos sociais de crítica midiática. São Paulo: Paulus, 2006.

BRASIL. Congresso Nacional. Lei n ${ }^{\circ} 11.652$ de 7 de abril de 2008. Institui os princípios e objetivos dos serviços de radiodifusão pública explorados pelo Poder Executivo ou outorgados a entidades de sua administração indireta; autoriza o Poder Executivo a constituir a Empresa Brasil de Comunicação - EBC; altera a Lei no 5.070, de 7 de julho de 1966; e dá outras providências. Diário Oficial da União, Poder Executivo, Brasília, DF, 8 abr. 2008. Disponível em: <https://goo.gl/WL3066>. Acesso em: 28 jan. 2017

CHRISTOFOLETTI, R.; MOTTA, L. G. Observatórios de mídia: olhares da cidadania. São Paulo: Paulus, 2008.

DAGNINO, E. Cultura, cidadania e democracia: a transformação dos discursos e práticas na esquerda latino americana. In: ALVAREZ, S.; DAGNINO, E.; ESCOBAR, A. (Orgs.). Cultura e política nos movimentos sociais latino americanos: novas leituras. Belo Horizonte: UFMG, 2000.

ESTEVES, J. P. A ética da comunicação e os media modernos: legitimidade e poder nas sociedades complexas. Lisboa: Fundação Calouste Gulbenkian, 2007.

$16 \frac{\text { Comunicação \& Inovação, PPGCOM/USCS }}{\text { v. 18, n. } 37 \text { (1-17) maio-ago } 2017}$ 
Espaço público e democracia: comunicação, processos do sentido e identidade sociais. São Leopoldo: Unisinos, 2003.

Sociologia da comunicação. Lisboa: Fundação Calouste Gulbenkian, 2011.

GOMES, W. Esfera de visibilidade pública e comunicação de massa. In: GOMES, W.; MAIA, R. C. M. Comunicação e democracia: problemas e perspectivas. São Paulo: Paulus, 2008.

HABERMAS, J. Direito e democracia: entre facticidade e validade, volume 1. Rio de Janeiro: Tempo Brasileiro, 1997.

Mudança estrutural da esfera pública. Rio de Janeiro: Tempo Brasileiro, 1984

SILVA, S. Estado, democracia e internet: requisitos democráticos e dimensões analíticas para a interface digital do Estado. 2009. Tese (Doutorado em Comunicação e Política) - Universidade Federal da Bahia, Salvador, 2009.

TÉLLEZ, M. P. Observatório e ouvidorias: experiências de crítica midiática e cidadania na América Latina. 2011. Tese (Doutorado em Comunicação e Informação) - Universidade Federal do Rio Grande do Sul, Porto Alegre, 2011.

WEBER, M. H. Estratégias da comunicação de Estado e a disputa por visibilidade e opinião. In: KUNSCH, M. (Org.). Comunicação pública, sociedade e cidadania. São Caetano do Sul: Difusão, 2011. . Um jeito perverso de entrar para a história. Observatório de Comunicação Pública, Porto Alegre, 2016. Disponível em: <https://goo.gl/JflxF2>. Acesso em: 13 set. 2016.

WEBER, M. H.; CARNIELLI, F. Z. A comunicação de instituições públicas e o paradoxo da visibilidade estratégica. In: ENCONTRO NACIONAL DAASSOCIAÇÃO NACIONAL DOS PROGRAMAS DE PÓS-GRADUAÇÃO EM COMUNICAÇÃO, 25., 2016, Goiânia. Anais... Goiânia: Compós, 2016. 